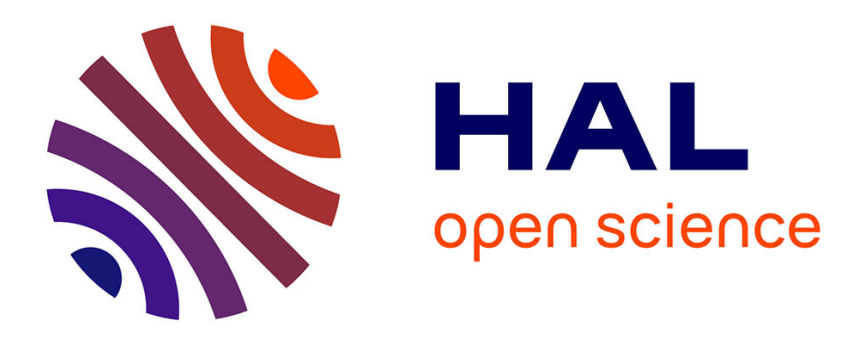

\title{
Atomic structure of "vitreous" interfacial films in sialon
}

\author{
Alain Thorel, J.Y. Laval, Daniel Broussaud
}

\section{To cite this version:}

Alain Thorel, J.Y. Laval, Daniel Broussaud. Atomic structure of "vitreous" interfacial films in sialon. Journal de Physique Colloques, 1988, 49 (C5), pp.C5-289-C5-292. 10.1051/jphyscol:1988534 . jpa00228031

\section{HAL Id: jpa-00228031 https://hal.science/jpa-00228031}

Submitted on 1 Jan 1988

HAL is a multi-disciplinary open access archive for the deposit and dissemination of scientific research documents, whether they are published or not. The documents may come from teaching and research institutions in France or abroad, or from public or private research centers.
L'archive ouverte pluridisciplinaire HAL, est destinée au dépôt et à la diffusion de documents scientifiques de niveau recherche, publiés ou non, émanant des établissements d'enseignement et de recherche français ou étrangers, des laboratoires publics ou privés. 


\title{
ATOMIC STRUCTURE OF "VITREOUS" INTERFACIAL FILMS IN SIALON
}

\author{
A. THOREL, J.Y. LAVAL ${ }^{*}$ and D. BROUSSAUD \\ Ecole des Mines de Paris, centre des Matériaux, BP 87 , \\ F-91003 Evry Cedex, France \\ "Laboratoire des Microstructures, CNRS-ESPCI, 10, rue vauquelin, \\ F-75231 Parts Cedex 05, France
}

\begin{abstract}
Atomic resolution imaging of siliceous interfacial films in a sialon has been achieved using transmission electron microscopy at $1000 \mathrm{KV}$. Although such films have always been reputed as vitreous, we show that they are at least partially crystallized. An atomic model is proposed and simulated. The stability of these films is discussed when special crystallographic relationships exist between the two adjacent grains.

Résumé : Des images de résolution atomique de films siliceux interfaciaux ont été enregistrées en microscopie électronique à $1000 \mathrm{KV}$. Quoique de tels films aient toujours été considérés comme vitreux, on montre qu'ils sont en fait partiellement cristallisés. Un modèle atomique est proposé et simulé. La stabilité de tels films est discutée lorsque des relations cristallographiques particulières existent entre les deux grains adjacents.
\end{abstract}

\section{Introduction}

The studied material is a low substituted yttria doped $\beta^{\prime}-$ sialon with the stoechiometric formula $\mathrm{Si}_{5.6} \mathrm{Al}_{0.4} \mathrm{O}_{0.4} \mathrm{~N}_{7.6}$. Previous microstructural investigations evidenced the glassy nature of the intergranular phase which has been found to be strongly related to the impurity content ( $\mathrm{Ca}, \mathrm{Fe}$ ) (1). Even if this glassy phase is mostly gathered at triple or quadriple junctions, the presence of 10 A-wide siliceous interfacial films has already been reported (2). Such films have been observed in silicon nitride based materials : they were described as vitreous $(3,4)$. In order to explain the constant thickness of such interfacial films clarke suggested recently that a structural disjoining pressure must act in order to separate the two adjacent grains : he assumed that this force was probably due to a certain ordering of the first layers of $\mathrm{SiO}_{4}$ tetrahedra at the immediate vicinity of the grains $(5,6)$. Moreover by high resolution electron microscopy and contrast simulation we evidenced such a periodic 5 to $10 \mathrm{~A}$ thin arrangement at crystal/glass interfaces along $\beta^{\prime}(1010)$ planes. Contrast simulation images of this configuration based on the structure of a silicate (dalyite) fit well the actual observations (7). It is to be noted that simultaneous HREM observation of a $\beta^{\prime}$ sialon grain and its attached dalyite layer at a crystal/glass interface is made possible by the topotaxy between these two phases. We then considered that an interfacial film can be compared in a first approximation to two crystal/glass interfaces brought together (fig. 1). We attempted in this work to reveal the existence of a periodic structure in such films.

\section{Experimental procedures}

HREM investigations have been achieved on the high resolution electron microscope JEOL ARM 1000 operating at $1000 \mathrm{kV}$ at the National Center for Electron Microscopy (U.C. Berkeley). Thin foils were obtained by ion-milling under standard conditions.

In order to get a $\beta^{\prime}(1010)$ interface edge-on and a structure image at least on one side of the interface, we systematicaliy searched for [0001] orientations. 
The computer assisted tilting stage allowed to set the orientation with an accuracy better than $1 \mathrm{mrad}$; by computed simulation we verified that such a misorientation induces absolutely no effect. on the observed HREM structure image.Contrast simulations are based on the previously proposed crystal/glass interface model (7) (fig. 2); they have been restricted to the side of the interface which exhibits the [0001] orientated grain and the presumed silicate layer. This restriction will be justified in the discussion.

\section{Results and discussion}

Fig. 3 and Fig. 4 show low-angle boundaries. These low energy boundaries do not need any intermediate layer to minimize their energy : in this case, the energy of the interface is related to the stress elastic field surrounding the interfacial dislocations. Similar configurations can probably be found for other special boundary misorientations. Since all the boundaries are supposed to be wetted by the liquid phase at sintering temperature, dewetting occurs for special boundaries during cooling down via a nucleation mechanism (8). Fig. 5 displays a wet general boundary for clefocus df $=-700,-600 \mathrm{~A}$. The most important feature is the presence of an ordereci atomic arrangement at the surface of the [0001] orientated grain. Contrast simulations indicate that this configuration can be described in a first approximation with the previous model based on the dalyite structure. The reason why there is no visible feature in the second half of the film might be that this part of the film remained glassy. But it can be assumed too that the same kind of epitaxially-grown silicate structure also exists at the surface of the second grain but cannot be imaged, since this grain usually has a random misorientation (fig. 6). In the present case only double fringes relative to (1010) planes perpendicular to the interface are imaged. The observation of a film structure in its whole width with a structure image on both adjacent grains is highly improbable since this situation would often describe a special boundary where an interfacial film is not stable.

Another example with (2130) fringes on one crystal is presented in Fig. 7 . Periodic features are again visible at the surface of the lower grain. This topotactic description of an interfacial film provides an easy interpretation of the suggested structural disjoining pressure : it begins to act as soon as the two silicate layers get into contact. The region which links the two intermediate silicate tetrahedral arrangements in the film is then supposed to be strongly distorted since it has to accommodate attractive forces and misorientation. Finally the lack of any electron beam irradiation induced effect on these films is consistent with the hypothesis of a crystalline structure (9) and seems to indicate that their composition is rather pure.

\section{Concluding remarks}

The percolation threshold of boundaries wetted by a second phase is approximately. $20 \%(10)$. That means that if the material exhibits only two interfacial films over ten observed boundaries, bulk properties - i.e. mechanical properties - begin to be influenced by the nature of these interfacial films. It was then of prime importance to demonstrate that the actual structure of such films was distinct from the "glassy" one which was generally accepted in the literature. Such an ordered structure is thought to withstand a normal stress and to inhibit grain boundary sliding at high temperature. As far as mechanical properties are concerned an ideal material would be the one in which all the bulk glass at triple junctions disappears to the profit of the wetting of boundaries by an interfacial film (9). A promising way to do so is provided by post-sintering hot isostatic treatment carried out on a liquid-phase-sintered material.

\section{References}

(1) Thorel, A., Laval J.Y., Kihn, Y, Sevely, J. Proceedings of ICXOM 11, (1986) $347-350$

(2) Thorel, A., Laval, J.Y., Broussaud, D., J. de Physique, Colloque C1, supplément 
au $\mathrm{n}^{\circ} 2$, tome $47,(1986) \mathrm{C} 1-353$

(3) Clarke, D.R., Thomas G. J. Am. Ceram. Soc., 60 [11-12] (1977) 491-95

(4) Lou, L.K.V., Mitche1l, T.E. and Heuer,A.H., J. Am. Ceram. Soc., 61 [9-10] (1978) 392-96

(5) Clarke, D.R., J. de Physique, C: (1985) 51-59

(6) Clarke, D.R., J. Am. Ceram. Soc. 70 [1] (1987) 15-22

(7) Thorel, A., Laval, J.Y., Broussaud, D. Teste de Sagey, G., Schiffmacher, G., Proceedings of JIMIS-4 (1986), supplément to Transactions of the Japan Institute of Metals, 819-826.

(8) Clarke, D.R., Annual Review in Materials Science, in press

(9) Laval, J.Y., Delamarre, C., Amamra M.C., Broussaud, D. J. Mater. Sci. 20 (1985) 381-390

(10) Shante, V.K.S., Kirkpatrick, S.I., dv. Phys. 20 (1971) 325

\section{Acknowledgements}

The authors are very grateful to $K . H$. Westmacott and $G$. Thomas for their hospitality at the N.C.E.M. (Lawrence Berkeley Laboratory, U.C. Berkeley). C. Nelson (microscopy), M. O'Keefe, R. Kilaas (contrast simulation) as well as G. Beauvais and $S$. Beurel (CNRS-ESPCI) were of most valuable help to carry out this study.

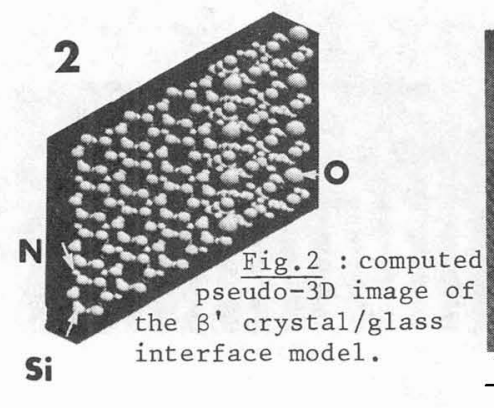

Fig. 4 : Similar type of low angle boundary as in Fig. 3 but slightly misoriented $(\mathrm{d}(10 \overline{10})=6.6 . \mathrm{A}, \mathrm{EM} \mathrm{430,300 \textrm {KV }})$
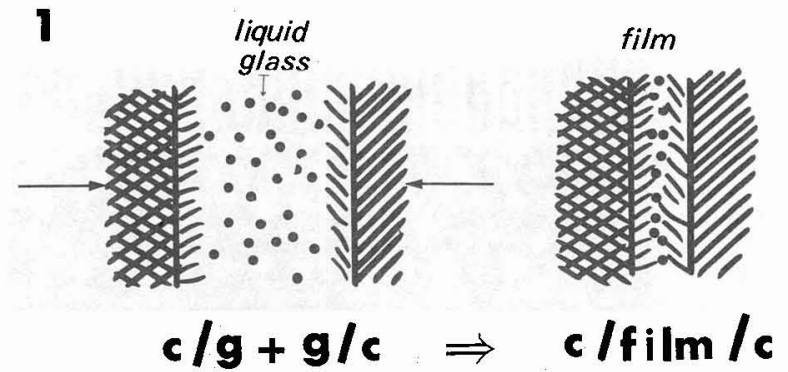

Fig.1 : Schematic of a film formation at sintering Eemperature from 2 crystal/glass interfaces.

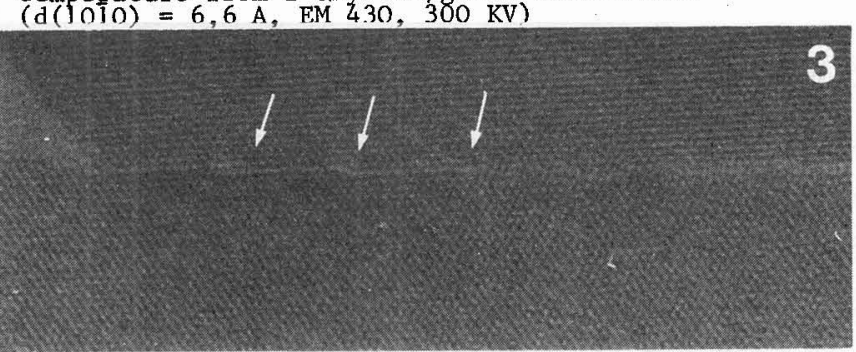

Fig.3 : Low angle boundary close to $\Sigma 1$. (0001) basal plane structure is imaged on both grain and reticular stens are arrowed. $(\mathrm{d}(10 \overline{1} \mathrm{O})=6.6 \mathrm{~A}, \mathrm{FM} 430,300 \mathrm{KV})$

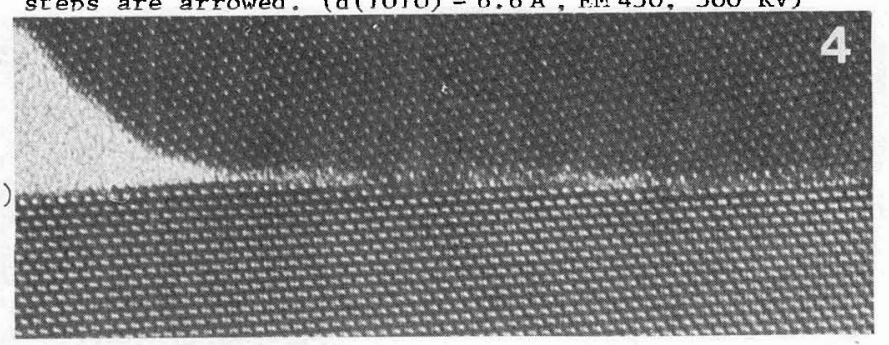


Tig.5 : Interfacial film (JEOL ARM 1000, $1000 \mathrm{kV}$ )
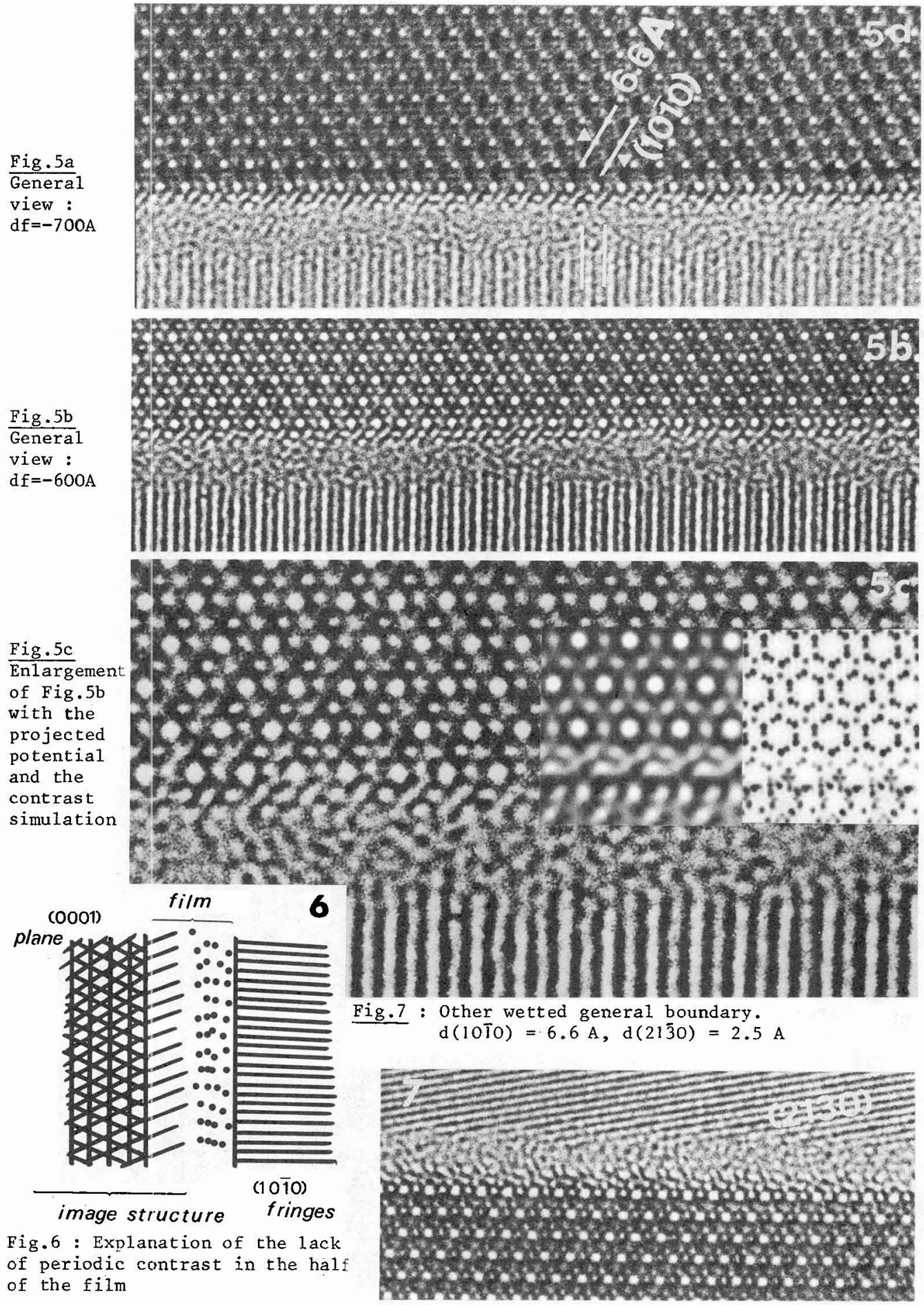